\title{
Study of HSG findings in our clientele: a multicentre retrospective analytical study
}

\author{
Shahla Yazdani*, Deepak Patil, Sujoy Mitra
}

Department of Obstetrics and Gynaecology, Command Hospital Air Force, Bangalore, Karnataka, India

Received: 30 December 2021

Accepted: 02 January 2022

\author{
*Correspondence: \\ Dr. Shahla Yazdani, \\ E-mail: a.shahla@gmail.com
}

Copyright: () the author(s), publisher and licensee Medip Academy. This is an open-access article distributed under the terms of the Creative Commons Attribution Non-Commercial License, which permits unrestricted non-commercial use, distribution, and reproduction in any medium, provided the original work is properly cited.

\begin{abstract}
Background: Infertility is a social morbidity for an infertile couple. The treatment is exhaustive and expensive. Methods: Hysterosalpingography is a basic investigation for an infertile lady. We assessed the findings and outcome of HSG over one year at our tertiary care centers.

Results: Bilateral patent fallopian tubes and normal uterine cavity were the commonest finding. Pain was the commonest complication in the procedure. Going for diagnostic hystero-laparoscopic was the commonest surgical intervention following HSG. Starting ATT was the commonest medicine intervention. ART Treatment involved starting intrauterine insemination cycle following HSG. Spontaneous conception was a welcome outcome in a selected subset of patients.

Conclusions: HSG is an inexpensive and OPD based investigative modality. It is effective test for evaluation of infertility especially in low-resource settings. It is a stepping stone to guide further treatment in an infertile couple. A well timed and well exposed film can give numerous insights about the options for cure of this morbidity.
\end{abstract}

Keywords: Fallopian tubes, Bicornuate uterus, HSG, Infertility

\section{INTRODUCTION}

Infertility is a major morbidity for couples across all age groups and societies. Infertility is a common reproductive health problem defined as the failure to achieve a pregnancy after one year of unprotected, regular sexual intercourse (according to world health organization). It affects approximately over $15 \%$ of couples of reproductive age. Infertility is primary if the couples had never been pregnant whereas secondary infertility is the inability to get pregnant after an earlier pregnancy which may or may not have been led to live birth. ${ }^{1}$

Hysterosalpingography was first performed in 1910 by German physician Rindfleisch by injecting Bismuth solution in the uterine cavity. ${ }^{2}$ It is non-invasive, costeffective method on investigation in outpatient setting. It is highly accurate tool as initial diagnostic modality of an infertile lady. ${ }^{3}$ Over the years in spite of various advances in ART, HSG has remained an integral part of evaluation of a lady with infertility. It gives numerous findings in the tubes and uterine cavity which guides the treatment. ${ }^{4}$

\section{Objectives}

This study primarily aims to analytically assess correlation of abnormal HSG findings and the infertility outcome in our clientele. This study aims to reiterate and highlight the importance of this modality of investigation and its immense utility in our day-to-day practice of treating infertile couples especially in low resource settings. 


\section{METHODS}

This was a multicentric, retrospective, analytic study of all patients undergoing HSG at tertiary care ART centers of Armed forces.

\section{Study design, location, duration and sample size}

Current study was retrospective, analytic study conducted at multicentric locations namely; Military Hospital, Agra, 151 Base Hospital, Guwahati and Command Hospital Airforce Bangalore. The study was conducted for one year from 01 January 2018 to 31 December 2018. Total participants in current study were 139.

\section{Inclusion criteria}

All cases of infertility registered at the centre's were included in the study. All hematological and biochemical evaluation were assessed and optimized on registration.

\section{Exclusion criteria}

Patients on ATT, acute PID and with severe male factor were excluded from the study.

\section{Procedure}

Following Informed consent patients were scheduled for HSG in proliferative stage of the cycle. Tablet Misoprost from Cipla Pharmaceutical containing Misoprostol, 400 mcg was applied vaginally at night before the procedure. Capsule Doxicip from Cipla Pharmaceuticals containing Doxycline $200 \mathrm{mg}$ was given $2 \mathrm{~h}$ before the procedure. InjHyowell from Wellona Pharmaceuticals containing 20 mg of Hyoscine Butyl bromide Buscopam was given before the procedure. The cervix was visualised and held with vulsellum. Karman cannula was used to push the dye. First X-ray was taken after instilling $5 \mathrm{ml}$ of Urograffin Dye and second film was taken after further 5 $\mathrm{ml}$ of Dye. Digital X-rays were studied, reported and findings compiled. Any difficulty and complication in the procedure were recorded and studied. Outcome following HSG was followed for six months.

\section{Statistical analysis}

All the data was analysed using Chi square test for observations of HSG findings so that any relationship of abnormal HSG findings in our clientele could be correlated with their outcomes.

\section{RESULTS}

139 HSG procedures were done in our study period. Majority of patients had primary infertility (59\%). The procedure was deferred/ rescheduled in 14 patients due to various reasons. In tubal evaluation $56 \%$ patients had bilateral patent tubes and $16 \%$ had bilateral tubal block. Hydrosalphinx in one or both tubes was present in 9 patients. Normal uterine cavity was found in $69 \%$ of patients. Anatomic defects were seen in the cavity in 11 patients. Intravasation of dye and evidence of Asherman Syndrome were seen in 3 patients each. In ladies with bilateral tubal occlusion $58 \%$ had fimbrial block. Level of block in unilateral block was cornual in $51 \%$ of cases (Table 1-2).

Table1: Demographic data.

\begin{tabular}{|llllll|}
\hline Parameters & & & & & \\
\hline \multirow{2}{*}{ Age $($ years $)$} & $<\mathbf{2 5}$ & $\mathbf{2 5 - 3 0}$ & $\mathbf{3 1 - 3 5}$ & $\mathbf{3 6}-\mathbf{4 0}$ & $\mathbf{> 4 1}$ \\
\cline { 2 - 6 } & 11 & 22 & 42 & 31 & 33 \\
\hline \multirow{2}{*}{ BMI $\left(\mathbf{k g} / \mathbf{m}^{\mathbf{2}}\right)$} & $<\mathbf{1 8}$ & $\mathbf{1 8 - 2 3}$ & $\mathbf{2 4 - 2 5}$ & $>\mathbf{2 6}$ & - \\
\cline { 2 - 6 } & 02 & 84 & 31 & 12 & - \\
\hline
\end{tabular}

Table 2: Basic data, tubal and intra-cavitary findings.

\begin{tabular}{|ll|}
\hline Parameters & N $(\%)$ \\
\hline Basic data & 139 \\
\hline Total HSG & $83(59)$ \\
\hline Primary infertility & $56(40)$ \\
\hline Secondary infertility & $6(4)$ \\
\hline Deferred & $8(5)$ \\
\hline Repeat /inconclusive & $79(56)$ \\
\hline Tubal findings & $37(26)$ \\
\hline Bilateral patent tubes & $23(16)$ \\
\hline Unilateral tubal block & $9(6)$ \\
\hline Bilateral tubal block & $11(7)$ \\
\hline Hydrosalphinx & $7(5)$ \\
\hline Rigid tube & $9(6)$ \\
\hline Loculated spill & $3(2)$ \\
\hline Constrictions/beaded tubes & \\
\hline Evidence of previous surgery & $97(69)$ \\
\hline Finding in cavity & $13(9)$ \\
\hline Normal cavity & $9(6)$ \\
\hline Filling defects & $11(7)$ \\
\hline Synechia & $3(2)$ \\
\hline Anatomic defects & $7(5)$ \\
\hline Intravasation dye & $3(2)$ \\
\hline Irregular cavity/endometritis & $11(7)$ \\
\hline Asherman syndrome & \\
\hline Calcification & \\
\hline
\end{tabular}

In our cohort of patient severe pain requiring additional parentral pain killers were required in 19 patients. Admission due to immediate or delayed complication was required for 3 ladies. Vaginal septum and cervical polyp requiring excision were seen in 1 and 4 ladies respectively. Radiolucent shadow of ureteric stone was seen in one patient. Diagnostic laparohysteroscopy was required in 43 patients. Anti-tubercular therapy was initiated following HSG and other coroborrative tests in 11 patients. 13 ladies conceived spontaneously within 6 mo of HSG. IUI was recommended in 63 ladies for further treatment. IVF-ET cycles were started in 29 ladies (Table 3). Patient distribution for primary infertility was maximum in $30-35 y$ category for primary infertility the 
same for secondary infertility was in 35-40 years category. Bilateral patent tubes and blocked tubes were seen in 74 and 23 patients respectively.

Table 3: Level of tubal block.

\begin{tabular}{|lllll|}
\hline Parameters & Cornual & Midtubal & Fimbrial & Total \\
\hline $\begin{array}{l}\text { Bilateral } \\
\text { tubal block }\end{array}$ & 13 & 6 & 27 & 46 \\
\hline $\begin{array}{l}\text { Unilateral } \\
\text { tubal block }\end{array}$ & 19 & 7 & 11 & 37 \\
\hline
\end{tabular}

Total 79 patients had normal radio-opaque shadow of uterine cavity.46 ladies had some abnormality which warranted further investigation. $62 \%$ patients had no abnormality detected on laparohysteroscopy. IUI was maximally recommended treatment in ladies of age group $30-35$ years $(26 \%)$ whereas IVF-ET was the maximally recommended treatment in 35-40 year age category (37\%) (Table 4). Spontaneous pregnancy occurred in $44 \%$ patients in age category 30-35years. 18 pregnancies were seen in ladies with BMI in normal range. More than $80 \%$ of spontaneous pregnancies were noticed in ladies with less than 5 years of infertility. More pregnancies were seen in ladies with primary infertility $(68 \%)$ as compared to secondary infertility cohort (32\%).3 spontaneous conceptions were seen in ladies with unilateral block.14 of 19 ladies with spontaneous conception had no abnormality in uterine cavity (Table $5)$.

\section{Ethnicity and socioeconomic class}

All subjects in the study were Asians of middle income as per modified Kuppuswamy scale.

\section{DISCUSSION}

HSG is an inexpensive outpatient investigative modality. It provides an insight into the female genital tract. A well exposed film can give numerous factors hampering fertility. Traditionally it is felt that HSG serves as a screening modality for further evaluation by more invasive tests. In resources poor setting like ours it is essential to utilise more efficient cheaper alternatives before subjecting the couple to more expensive options of evaluation. On the contrary some researcher feel laparoscopy is essential investigations in ladies in spite of normal report of HSG. ${ }^{5}$ In our study population $59 \%$ of patients had primary infertility. Age distribution showed maximum distribution in $30-35$ years $(34 \%)$ for primary infertility. For secondary infertility the maximum distribution was in 35-40 years category. Bilateral patent tubes were seen in 79 patients $(56 \%)$. Normal Uterine cavity was seen in 97 patients $(69 \%)$. In less than $2 \%$ patient the study had to be repeated due to inconclusive study.
Table 4: Complications, incidental findings and outcome following HSG study.

\begin{tabular}{|ll|}
\hline Parameters & $\mathbf{N}(\%)$ \\
\hline Complications & $19(13)$ \\
\hline Severe pain & $4(2)$ \\
\hline Infection PID & $2(1)$ \\
\hline Vaso vagal shock & $3(2)$ \\
\hline Inconclusive finding & $2(1)$ \\
\hline Vaginismus & $3(2)$ \\
\hline Admission & $\mathbf{N}$ \\
\hline Incidental findings & 1 \\
\hline Vaginal septum & 6 \\
\hline Cervical poly & 9 \\
\hline Pin hole meatus & 4 \\
\hline Hypersensitivity drugs & 1 \\
\hline Renal stone disease & \\
\hline Outcomes & $43(30)$ \\
\hline DHL & $11(7)$ \\
\hline ATT & $9(6)$ \\
\hline Antibiotics & $6(4)$ \\
\hline Cryocautery & $19(13)$ \\
\hline Spontaneous pregnancy & 1 \\
\hline Septal excision & $63(45)$ \\
\hline IUI Cycles & $29(20)$ \\
\hline IVF-ET & \\
\hline
\end{tabular}

Linda Renbaum found injection pressure and exposure of film affecting intra-observer assessment. Film timing also affect the study of tube anatomy and depiction of uterine contours. ${ }^{6}$ Bilateral patent tubes were seen in $56 \%$ of our cohort. Unilateral tubal block was seen $26 \%$ and bilateral block was seen in $16 \%$ of ladies. Bilateral tubal block patients were referred for further work up. This included endometrial thickness pattern, X-ray chest, endometrial Biopsy for TBPCR and diagnostic laparohysteroscopy in selected cases. HPE, Culture and AFB staining has low sensitivity for detection of Genital tuberculosis. PCR is more sensitive and specific for detection of tubercular affection of female genital tract in cases of early disease and clinically suspected cases. ${ }^{7}$ Hydrosalphinx was seen in 9 patients. Four of these had history of recurrent PID. Three of these were started on ATT. Xinyun Yang et al found hydrosalphinx to be a bad prognostic marker for outcome of IVF. In a study of 42 patients with radiologically guided micro coil embolisation versus 113 patients with laparoscopic salpingectomy, they found similar pregnancy and implantation rate in both groups. Embolisation of tubes proximal to hydrosalphinx is less invasive and better option. ${ }^{8}$ Zeyneloglu also saw that hydrosalphinx if bilateral and evident on TVS before $\mathrm{COH}$ portends a poor implantation and pregnancy rate. ${ }^{9}$ Rigid tubes and loculated spills were seen in 11 and 7 patients. These proved to be corroborative findings for starting ATT. These reflected as signs of chronic inflammation followed by calcification and adhesion formation. 
Table 5: Overall patient distribution $(n=139)$.

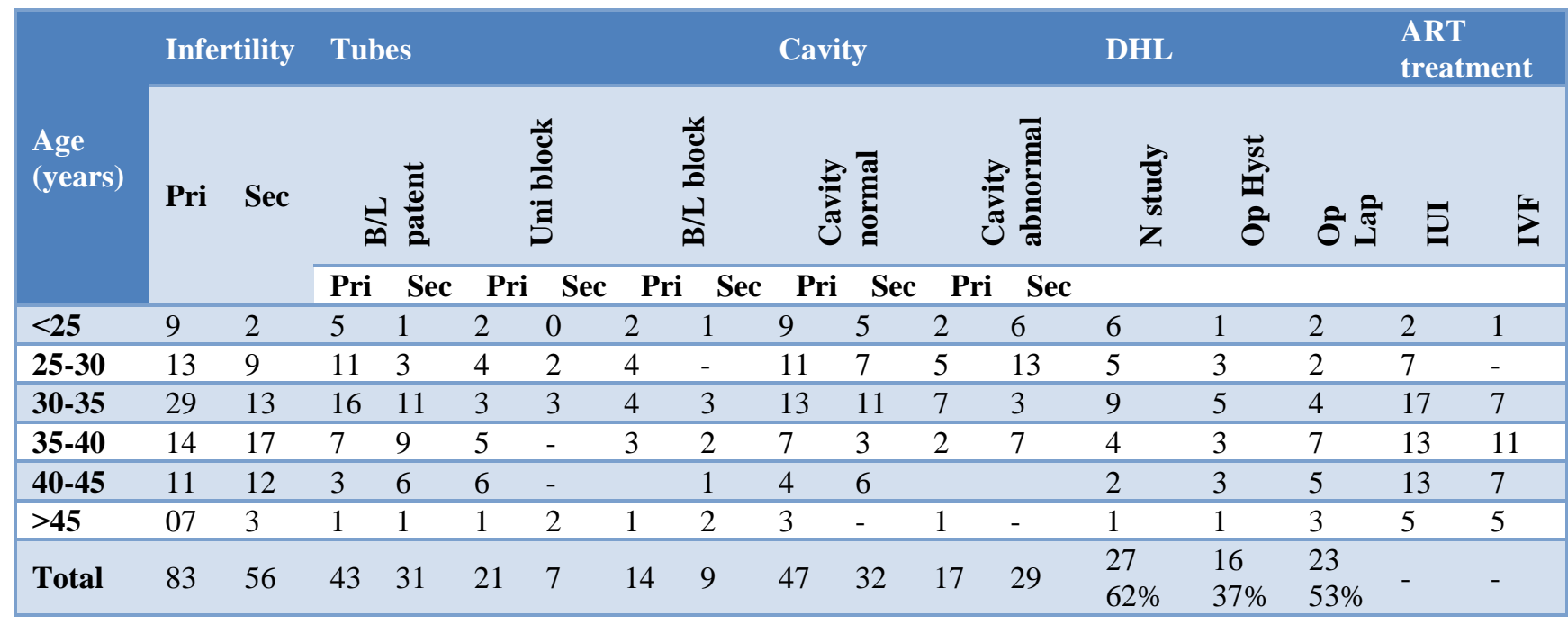

Table 6: Patient distribution in cases of spontaneous pregnancy $(n=19)$.

\begin{tabular}{|c|c|c|c|c|c|c|c|c|c|c|c|c|c|c|}
\hline \multirow{2}{*}{$\begin{array}{l}\text { Age } \\
\text { distribution } \\
\text { (years) }\end{array}$} & \multicolumn{2}{|l|}{ BMI } & \multicolumn{2}{|c|}{ Duration of Inf } & \multirow{2}{*}{$\begin{array}{l}\text { Pri } \\
\text { Inf }\end{array}$} & \multirow{2}{*}{$\begin{array}{l}\text { Sec } \\
\text { Inf }\end{array}$} & \multicolumn{2}{|c|}{$\begin{array}{l}\text { Tubes B/L } \\
\text { patent }\end{array}$} & \multicolumn{2}{|c|}{$\begin{array}{l}\text { Tubes } \\
\text { unilateral } \\
\text { block }\end{array}$} & \multicolumn{2}{|c|}{$\begin{array}{l}\text { Cavity } \\
\text { normal }\end{array}$} & \multicolumn{2}{|c|}{$\begin{array}{l}\text { Cavity } \\
\text { abnormal }\end{array}$} \\
\hline & 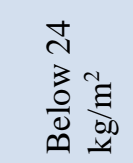 & 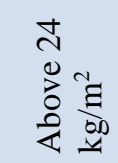 & 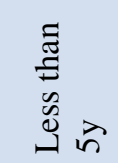 & 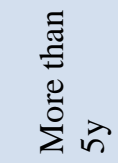 & & & $\Xi$ & $\infty$ & $\equiv$ & ש & $\equiv$ & 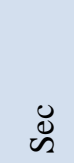 & $\equiv$ & $\infty$ \\
\hline$<25$ & 2 & - & 3 & - & 2 & - & 2 & - & - & - & 1 & - & 1 & - \\
\hline $25-30$ & 5 & - & 4 & 1 & 6 & 1 & 4 & 1 & 2 & - & 4 & 1 & 2 & - \\
\hline $30-35$ & 7 & 1 & 5 & 2 & 4 & 2 & 3 & 2 & 1 & - & 3 & 1 & 1 & 1 \\
\hline $35-40$ & 3 & - & 3 & - & - & 3 & - & 3 & - & - & - & 3 & - & - \\
\hline $40-45$ & 1 & - & 1 & - & 1 & - & 1 & - & - & - & 1 & - & - & - \\
\hline$>45$ & - & - & - & - & - & - & - & - & - & - & - & - & - & - \\
\hline Total & 18 & 1 & 16 & 3 & 13 & 6 & 10 & 6 & 3 & & 9 & 5 & 4 & 1 \\
\hline
\end{tabular}

Kochorova found these signs in $63 \%$ of patients with long standing and non-active tubercular infection of tubes. ${ }^{10}$ In three patients we saw evidence of previous surgery. Two had undergone unilateral salpingectomy for ectopic pregnancy. One HSG was done for pre-operation preparation for sterilisation reversal. It showed bilateral isthmic block. Sony Sierra saw that HSG is very invasive and probably should not be mandatory pre-operation requirement before reversal. Prevalence of abnormalities in proximal tubal segment identified in HSG is very low for it to be routinely done. ${ }^{11}$ Tadessein a study of 294 patients found that true positive rate for bilateral tubal block on HSG was $89 \%$. Location of tubal block is an important prognostic indicator. It was seen that more of cornual blocks were false positive as compared to mid tubal block on HSG. It was also found that a quarter of patient with cornual occlusion were false. False positive rate especially for cornual block was high. Fimbrial block were more amenable to surgical correction. ${ }^{12}$
In our cohort $26 \%$ ladies had unilateral tubal block.75\% of these had primary infertility. More than half of these had cornual block. $18 \%$ had mid tubal block. Ming hueilin in a study of 133 patients with unilateral tubal block found this finding to be of limited prognostic value.

This may be because of cornual spasm, under filling of dye in the tube or due to temporary plugging of tubes with debris/amorphous material. In ladies with unilateral block it was found that mid tubal block found on HSG had more of infective aetiology and poorer prognosis. The pregnancy rate is higher in ladies with unilateral cornual block (21\%) as compared to mid tubal block (12\%) and unexplained infertility (18\%). They found location of occlusion also affecting the outcome of IUI cycles. Proximal occlusion had pregnancy rate of $21 \%$ as compared to $12 \%$ for mid tubal occlusion in unilateral tubal block. This study also found cumulative pregnancy rate with 3 IUI cycles to be similar in patients with 
unilateral block and unexplained infertility. ${ }^{13}$ Jacob farhi in a case control study found $\mathrm{COH}$ Iui to be initial recommendation for treatment in ladies with proximal unilateral tubal block. They also found mid tubal and distal unilateral block to be a poor prognostic factor. ${ }^{14}$ Bilateral patent and blocked tube were similar in distribution in cases of primary or secondary infertility. $60 \%$ of ladies with bilateral tubal block had fimbrial occlusion as compared to cornual block in more than $50 \%$ of patient with unilateral block. Mid tubal block defined as obstruction to dye in ampullary or isthmic region was seen in $13 \%$ of patients with bilateral block and $18 \%$ of ladies with unilateral block. Nargess found midtubal occlusion to be more predictive of genital tuberculosis as compared to cornual and fimbrial block. ${ }^{15}$ SMH Shah found poor positive predictive value for bilateral proximal tubal block on HSG. Inspite of relatively limited value of accurately identifying tubal patency HSG remains a useful primary investigative tool. ${ }^{16}$ Commonest abnormality in the uterine cavity was of filling defect. ${ }^{17}$ In our cohort these were attributable to polyp, air bubble and synechia. They were seen in 9, 13 and $6 \%$ of our cohort. On HSG films, a smooth indentation of the radio opaque shadow was seen in cases of sub mucous fibroid. For endometrial poly filling defect was seen as pedunculated, protrusion in the cavity. Along with associated findings if indicated hysteroscopy was done. We found that most of the findings were false positive and Hysteroscopic excision was required in only $2(4 \%)$ of these. A Golan also found a high sensitivity $(98 \%)$ of HSG in detection of filling defects in uterine cavity, but a specificity of only $15 \%$. Benefit of HSG is its ease and a very high negative predictive value $(95 \%)$ as compared to hysteroscopy. ${ }^{18}$ _Anatomical defect was identified in 11 patients. Nine of these were due to septate uterus and one was attributive to bicornuate uterus. One was found to be false positive and due to poor exposure. Further evaluation with TVS and DHL were required in these cases. Hysteroscopicmetroplasty improved the uterine cavity and its restoration. Mullerian duct anomalies need a combined approach of imaging and endoscopy for optimal outcome of treatment. Subtle Mullerian ductanomalies may be overlooked by clinical and transvaginal scan may be picked up by a well exposed HSG. These may lead to early pregnancy loss if left untreated. Poonam in a similar population cohort found uterine anomaly rate of $20 \%$. It was found that an accurate interpretation of HSG is essential to avoid unnecessary invasive investigation and treatment. Anatomical defects detected on HSG were mostly due to congenital cause and rarely acquired type. A combined approach with HSG, hysteroscopy and sonography is essential for diagnosis of uterine anomaly. ${ }^{19}$ The prevalence of congenital anomaly in general population is $6.7 \%$ whereas the same in infertile population is $7.3 \%$. In general population the commonest anomaly is Arcuate uterus, the same in infertile ladies is septate uterus. ${ }^{20}$ Damage to endometrium due to varied reasons can lead to intravasation of dye. Altered endometrial vascularity and permeability may cause migration of dye in adjoining vasculature. Combination of various procedural and preprocedural factors may cause intravasation. Menometrorrhagia, previous abortions, painful procedure, Mullerian abnormalities and endometritis may cause Intravasation. ${ }^{21}$ In our cohort intravasation was seen in 3 patients $(2 \%)$. In 2 of these it was associated with evidence of irregular uterine cavity and mid tubal occlusion. On follow up with endometrial growth parameters and laparoscopy both were started on ATT. The third patient was given outpatient management for PID for endometritis.

In our cohort, intrauterine adhesions were found in 3 patients. All of them were cases of secondary infertility. Two of these had more than 2 early pregnancy loss followed by surgical evacuation. One had history of retained placenta. Eva Dreisler found that incidence of IUA and Asherman syndrome ranges from 2-40\% based on population studied. Most of the cases are caused by damage to decidua basalis due to repeated curettage following pregnancy termination. Severity of adhesions is proportional to number of curettage procedures done. Common non obstetric reasons for asherman syndrome include prior hysteroscopic surgery, uterine artery embolisation or tuberculosis. $^{22}$

Drug allergy was seen in $2 \%$ of ladies. 3 patients developed severe cramp in lower abdomen with spotting. This may be attributed to PGE1 vaginal application preprocedure. One patient had nausea and GI upset likely due to oral prophylactic dose of Cap doxycycline antibiotic pre-procedure. Pain mild to moderate was felt by most of the patients. Severe pain requiring additional Parentral pain killer and observation in OPD was required in $13 \%$ of cases. We observed that counselling patients about the procedure was essential to reduce pain and apprehension amongst our clientele. Our counselling also involved educating couples about necessity of the test and its implication on future treatment. In 5 out of 9 patients who were deferred, we could do the procedure after thorough counselling. Majority of deferrals were due to anxiety and apprehension about the procedure. Guvenc et al in a randomised control trial also found that patient education and counselling is an effective intervention to reduce the pain score. ${ }^{23}$ We used PGE-1 tablets vaginally, the night before in all patients for cervical softening. It facilitates the process and improves tolerance. Yiu Tai also found Tab Misoprostol to ease execution of the procedure. ${ }^{24}$ We had no incidence of cervical trauma and uterine perforation.Sabasohail study showed that increased procedure time and pre procedure apprehension may portend intolerable pain during the procedure of HSG. $^{25}$ In our cohort $3 \%$ of procedures had to be rescheduled due to severe apprehension or vaginismus. All of them could be done at later date with extensive counselling. 2 patients had to be given increased PGE1 vaginal dose for cervical softening. Pin hole meatus and primary infertility predisposed difficult cannulation of Leech Wilkinson cannula.4 patients developed pelvic pain and fever following HSG. Clinically acute PID was 
diagnosed supported by imaging. They were hospitalised and given broad spectrum parentral antibiotics. Recovery was gradual and uneventful. BR Mollar found a similar incidence. C. trachomytis and M. Hominis are usually the pathogens. It is recommended that $C$. Trachomytis should be sought before the procedure and treated beforehand. ${ }^{26}$ We gave oral antibiotics before the procedure in all patients. Our low rate of infection $(2 \%)$ may be because of strict asepsis during the procedure and prophylactic antibiotics. Vaginismus is involuntary contraction of muscles of perineum and vaginal wall. It is both a physical and emotional disorder. ${ }^{27}$ Two patients in our cohort needed to be thoroughly counselled and rescheduled for severe vaginismus. Mildvaso vagal reaction was seen in less than $2 \%$ of ladies. It resolved without Atropine administration.

Genital tuberculosis is a global health problem and remains a major cause of female infertility especially in developing countries like ours. ${ }^{28}$ Genital tuberculosis has an incidence of about 5-9\% of infertile ladies. Tubercular involvement of fallopian tubes is the commonest affliction in $90 \%$ patients followed by endometrial cavity in $50 \% .^{29}$ The bacilli initially colonise the endometrium. Endometrial cavity irregularity may be the earliest indicator of infection. Synechia formation may lead to encroachment of the cavity. An obliterated cavity due to chronic inflammation leads to shrunken cavity. Healing phase may be marked by granuloma formation and calcification. Being endemic in developing countries it is a significant contributor to infertility. Timely start of ATT is essential to avoid permanent damage and long term sequalae. ${ }^{30}$ In spite of advances in USG, CT and MRI, HSG remains gold standard to assess the internal architecture of tubes and endometrium. ${ }^{16}$ Tubes may be encased with fibrotic scar tissue leading to rigid aperistaltic segment. Most of cases are asymptomatic and spread to adjacent structures of genitourinary tract usually starts from the tubes. In our cohort we saw synechia in the uterine cavity, Irregular cavity and micro calcification in $9(6 \%), 7(5 \%)$ and $11(7 \%)$ of patients. In some cases due to widespread ulceration and damage to deciduas basalis extravasations of dye may be seen in uterine venous and lymphatic channels. We saw intravasation of dye in $6(4 \%)$ of our patients. Genital TB was diagnosed based on endometrial growth pattern as an associated factor. Endometrial biopsy for TB PCR along with clinical findings was corroborated for starting ATT. HSG serves as a primary test for tubal function. In our study 79 patients had normal architecture, patent tubes. In others there was evidence of some tubal compromise. 30 $\%$ of our patients finally underwent DHL for various indications to further guide the treatment. In tubal findings were evaluated, suggestive of tuberculosis. Hydrosalphinx, rigid tubes was seen in 11 patients $(7 \%)$, loculated tubes were seen in 7 patients $(5 \%)$ and beaded tubes were seen in 9 patients $(6 \%)$. Donya et al found HSG to be safe, simple and inexpensive modality to study tubercular affliction of genital tract. ${ }^{31}$ In one patient we found aymptomatic ureteric calculi. There were no back pressure changes. Incidental finding of such stones usually need no surgical treatment. ESWL may be needed depending on size.

\section{Outcome}

HSG gave various finding suggestive of tuberculosis. These were corroborated with Mountoux test, ESR, endometrial growth pattern correlated endometrial biopsy for TB-PCR. ATT was started in 11 patients (7\%).Chavhan et al found same incidence in similar cohort of patients. They also found tubes to be the commonly affected site. ${ }^{32}$

DHL was done based on HSG and clinical findings. $30 \%$ of our patient underwent this operative intervention to further guide the treatment. Isao Tsuji found that $82 \%$ of ladies with bilateral tubal block had associated factors on DHL which warranted ART treatment. Whereas only $23 \%$ of patients were found to have requirement of ART treatment in ladies with unilateral tubal Block and associated findings on HSG. ${ }^{6}$ Being an OPD procedure HSG serves as a screening for more invasive and expensive operative intervention. Sandra found that only $29 \%$ cases showing unilateral or bilateral findings in HSG required IVF ET for treatment following laparoscopy. Thus, HSG acts to screen patients requiring DHL. Most of the patients with pathology detected on HSG can have correction with operative laparoscopy. ${ }^{33}$ IUI was recommended for treatment in $48 \%$ patients with minimal or no abnormality on laparoscopy. Laparoscopy might be needed inspite of normal HSG findings in selective patients to rule out endometriosis or distorted Tubo ovarian relationship. ${ }^{34}$ In our cohort of 43 patients were scheduled for DHL.62\% of patients had normal study with bilateral patent tubes on chromotubation. Operative hysteroscopy was required in $37 \%$ and op laparoscopy was done in 23 of 43 patients. Endometrial Polypectomy was done in 7 patients and septal excision was required in 5 patients. Operative laparoscopy involved fulguration of superficial endometriotic spots in 9 patients and excision of flimsy adhesions to restore Tubo ovarian relationship in 7 patients. 3 patients underwent excision of endometrioma. Vasilios et al found incidence of polyp in lower genital tract around 7-50\%. ${ }^{35}$ Cervical polyps are rarely a cause of infertility. Endometrial polyp in fundal or cornual region may impair fertility by mechanical effect or due to chronic inflammation. In our series of cases we did Polypectomy by cold knife. Cold knife and other mechanical means of treatment have lower post operative pain score. Spontaneous pregnancy happened in 19 patients in six month follow up post HSG. $80 \%$ of patients were below 35 years of age. All of these, except one occurred in ladies with normal BMI. $70 \%$ of these ladies with spontaneous pregnancy were primary infertility cases. Three fourth of all spontaneous pregnancies were in patients with bilateral patent tubes. One fourth of pregnancies also occurred in ladies with unilateral block. $70 \%$ of ladies had normal uterine cavity on HSG. Five 
patients had some abnormality in the HSG film proved to be false positive on hysteroscopy and 2 had flimsy adhesion band at the cornual. Positive prognostic factor for spontaneous pregnancy post HSG are young age and secondary infertility with normal HSG finding. With unilateral block chances of pregnancy remains high.Sarahmaheux in a study of more than 400 patients found a spontaneous pregnancy rate of $26 \% .^{36}$ Uterine flushing during the procedure might improve the chances of spontaneous conceptions. Immune modulation by oil based iodine contrast media also has been proposed for therapeutic effect of HSG. The T-helper 2 cells population promote pregnancy by aiding humoral immunity and suppressing immune rejection of embryo as a graft by the endometrium. Th1 and 2 imbalances may be causes of infertility. Th 2 type cells promote IL 2, 5 and 10 production and helping implantation. ${ }^{37}$ In our cohort we found a 13 of 139 ladies conceived spontaneously over 6 months of follow up. More than $60 \%$ were with primary infertility and rest had history of previous conceptions. Except one all these patients had BMI in the normal range. $73 \%$ had bilateral patent tubes, whereas 5 of 19 conceived inspite of unilateral tubal block. Further assessment of HSG finding revealed that normal cavity finding supports spontaneous conceptions. 14 of 19 had no abnormality in cavity, remaining 5 had false positive HSG findings which had been ruled out by hysteroscopic direct visualisation. We used oil-based dye in all cases. Wang et al found higher probability of spontaneous conception with oil-based contrast as compared to water soluble contrast. There were higher chances of venous intravasation and systemic thromboembolism with oil-based dyes. ${ }^{38}$ HSG remains a useful screening tool for varied etiologies to infertility. A glimpse of factors affecting uterine cavity, Tubes and adnexa can be achieved by a well exposed HSG film and keen evaluation of the film. Endoscopy and other latest tools in the armamentarium of ART specialist serves to compliment the findings. ${ }^{39}$

\section{Limitations}

Limitations of current study were; as the study was done taking into account finite time lines of HSG done in one year in our multicentric study, limited sample size was a limitation for a more elaborate analysis. Moreover, correlation of the HSG findings and laparscopy findings of all the subjects (infertility patients) would have been an ideal study but that was beyond the scope of this study.

\section{CONCLUSION}

HSG remains an invaluable tool in initial assessment of a lady with infertility. Numerous etiologies can be evaluated by this OPD based inexpensive modality. Genital tuberculosis and anatomic causes of infertility can be diagnosed with high accuracy. Pain moderate to severe was commonest complication of the procedure. Laparohysteroscopy was the commonest surgical intervention and starting ATT was the commonest medical intervention following HSG. Good prognostic factor for spontaneous pregnancy following HSG are normal BMI, less duration of infertility and normal HSG study. Well timed and well exposed HSG film gives numerous insight into factors affecting fertility. In resource poor setting, it is investigation of choice as initial screening test.

\section{ACKNOWLEDGEMENTS}

Authors would like to thank the team of residents, nursing officers, X-ray technicians and the ward sahayika (lady attendant) who assisted during the study.

\section{Funding: No funding sources}

Conflict of interest: None declared

Ethical approval: The study was approved by the Institutional Ethics Committee

\section{REFERENCES}

1. Borght MV, Wyns C. Fertility and infertility: Definition and epidemiology Clin Biochem. 2018; 62:2-10.

2. Rindfleisch W. Darstellung des cavum uteri. Klin Wochenscher. 1910;47:780.

3. Ludwin A, Ludwin I, Banas T, Knafel A, Miedzyblocki M, Basta A. Diagnostic accuracy of sonohysterography, hysterosalpingography and diagnostic hysteroscopy in diagnosis of arcuate, septate and bicornuate uterus. J Obstet Gynaecol Res. 2011;37(3):178-86.

4. Simpson WL, Beitia LG, Mester J. Hysterosalpingography: a reemerging study Radiographics. 2006;26(2):419-31.

5. Tsuji I, Ami K, Miyazaki A, Hujinami N, Hoshiai H. Benefit of diagnostic laparoscopy for patients with unexplained infertility and normal hysterosalpingography findings. Tohoku J Exp Med. 2009;219(1):39-42.

6. Renbaum L, Ufberg D, Sammel M, Zhou L, Jabara S, Barnhart K. Reliability of clinicians versus radiologists for detecting abnormalities on hysterosalpingogram films. Fertil Steril. 2002; 78(3):614-8.

7. Thangappah RB, Paramasivan CN, Narayanan S. Evaluating PCR, culture \& histopathology in the diagnosis of female genital tuberculosis. Indian J Med Res. 2011;134(1):40-6.

8. Yang X, Zhu L, Le F, Lou H, Zhao W, Pan P, Zou Y, Jin F. Proximal fallopian tubal embolization by interventional radiology prior to embryo transfer in infertile patients with hydrosalpinx: a prospective study of an off-label treatment. J Minim Invasive Gynecol. 2020;27(1):107-15.

9. Zeyneloglu HB. Hydrosalpinx and assisted reproduction: options and rationale for treatment. Curr Opin Obstet Gynecol. 2001;13(3):281-6. 
10. Kochorova MN, Semenovskiǔ AV. Features of hysterosalpingogram in verified genital tuberculosis. Probl Tuberk. 2001;(2):31-3.

11. Sierra S, McComb PF. Hysterosalpingography in the investigation of women requesting reversal of sterilization. Should it play a role? J Reprod Med. 2008;53(1):20-4.

12. Kitilla T. Tubo-peritoneal infertility: comparision of pre-operative hysterosalpingography and laparotomy findings (Tikur Anbessa Hospital, 1995 - 2002). Ethiop Med J. 2006;44(2):167-74.

13. Lin MH, Hwu YM, Lin SY, Lee RK. Treatment of infertile women with unilateral tubal occlusion by intrauterine insemination and ovarian stimulation. Taiwan J Obstet Gynecol. 2013;52(3):360-4.

14. Farhi J, Ben-Haroush A, Lande Y, Fisch B. Role of treatment with ovarian stimulation and intrauterine insemination in women with unilateral tubal occlusion diagnosed by hysterosalpingography. Fertil Steril. 2007;88(2):396-400.

15. Afzali N, Ahmadi F, Akhbari F. Various hysterosalpingography findings of female genital tuberculosis: A case series. Iran J Reprod Med. 2013; 11(6):519-524.

16. Shah SM, Towobola OA, Masihleho M. Diagnosis of fallopian tube patency. East Afr Med J. 2005; 82(9):457-62

17. Onwuchekwa CR, Oriji VK. Hysterosalpingographic (HSG) Pattern of Infertility in Women of Reproductive Age. J Hum Reprod Sci. 2017;10(3): 178-84.

18. Golan A, Eilat E, Ron-El R, Herman A, Soffer Y, Bukovsky I. Hysteroscopy is superior to hysterosalpingography in infertility investigation. Acta Obstet Gynecol Scand. 1996;75(7):654-6.

19. Poonam A. The role of hysterosalpingography in cases of subfertility Kathmandu. Univ Med J. 2007;5(4):456-60.

20. Saravelos SH, Cocksedge KA, Li T-C. Prevalence and diagnosis of congenital uterine anomalies in women with reproductive failure: a critical appraisal. Hum Reprod Update. 2008;14(5):415-29.

21. Dusak A, Soydinc HE, Onder H, et al. Venous intravasation as a complication and potential pitfall during hysterosalpingography: re-emerging study with a novel classification. J Clin Imaging Sci. 2013; 3:67.

22. Dreisler E, Kjer JJ. Asherman's syndrome: current perspectives on diagnosis and management. Int $\mathbf{J}$ Womens Health. 2019 Mar 20;11:191-98.

23. Guvenc G, Bektas Pardes B, Kinci MF, Karasahin KE. Effect of education and counselling on reducing pain and anxiety in women undergoing hysterosalpingography: A randomised controlled trial. J Clin Nurs. 2020;29(9-10):1653-61.

24. Bastu E, Celik C, Nehir A, Dogan M, Yuksel B, Ergun B. Cervical priming before diagnostic operative hysteroscopy in infertile women: a randomized, double-blind, controlled comparison of 2 vaginal misoprostol doses. Int Surg. 2013;98(2):140-4.
25. Sohail S. Variables affecting immediate pain tolerance in X-ray hysterosalpingography. J Coll Physicians Surg Pak. 2004;14(3):170-2.

26. Møller BR, Allen J, Toft B, Hansen KB, TaylorRobinson D. Pelvic inflammatory disease after hysterosalpingography associated with Chlamydia trachomatis and Mycoplasma hominis. Br J Obstet Gynaecol. 1984;91(12):1181-7.

27. Daňková Kučerová J, Machač Š, Vrzáčková P, Klapilová K, Kováŕ P, Zábranská L, Damborská Z, Wiecek P, Vrána T. Vaginismus - who takes interest in it? Ceska Gynekol. 2019;84(3):233-9.

28. Mondal SK. Histopathologic analysis of female genital tuberculosis: a fifteen-year retrospective study of 110 cases in eastern India. Turk Patoloji Derg. 2013;29(1):41-5.

29. Shah HU, Sannananja B, Baheti AD, Udare AS, Badhe PV. Hysterosalpingography and ultrasonography findings of female genital tuberculosis. Diagn Interv Radiol. 2015;21(1):10-5

30. Ishrat $S$, Fatima P. Genital tuberculosis in the infertile women - an update. Mymensingh Med J. 2015;24(1): 215-20.

31. Farrokh D, Layegh P, Afzalaghaee M, Mohammadi M, Fallah Rastegar Y. Hysterosalpingographic findings in women with genital tuberculosis. Iran $\mathbf{J}$ Reprod Med. 2015;13(5):297-304.

32. Chavhan GB, Hira P, Rathod K, Zacharia TT, Chawla A, Badhe P, Parmar H. Female genital tuberculosis: hysterosalpingographic appearances. $\mathrm{Br} \mathrm{J}$ Radiol. 2004;77(914):164-9.

33. Tanahatoe S, Lambalk C, McDonnell J, Dekker J, Mijatovic V, Hompes P. Diagnostic laparoscopy is needed after abnormal hysterosalpingography to prevent over-treatment with IVF. Reprod Biomed Online. 2008;16(3):410-5.

34. Mohammadbeigi R, Tanhaeivash R. Comparison of hysterosalpingography and laparoscopy in infertile Iranian women with tubal factor. Ginekol Pol. 2012 Nov;83(11):841-3.

35. Tanos V, Berry KE, Seikkula J, Abi Raad E, Stavroulis A, Sleiman Z, Campo R, Gordts S. The management of polyps in female reproductive organs. Int J Surg. 2017;43:7-16.

36. Maheux-Lacroix S, Bergeron C, Moore L, Bergeron MÈ, Lefebvre J, Grenier-Ouellette I, et al. Hysterosalpingosonography Is Not as Effective as Hysterosalpingography to Increase Chances of Pregnancy. J Obstet Gynaecol Can. 2019;41(5):593598.

37. Yun AJ, Lee PY. Enhanced fertility after diagnostic hysterosalpingography using oil-based contrast agents may be attributable to immunomodulation. AJR Am J Roentgenol. 2004;183(6):1725-7.

38. Wang R, van Welie N, van Rijswijk J, Johnson NP, Norman RJ, Dreyer K, Mijatovic V, Mol BW. Effectiveness on fertility outcome of tubal flushing with different contrast media: systematic review and network meta-analysis. Ultrasound Obstet Gynecol. 2019;54(2):172-81. 
39. Roma Dalfó A, Ubeda B, Ubeda A, Monzón M, Rotger R, Ramos R, Palacio A. Diagnostic value of hysterosalpingography in the detection of intrauterine abnormalities: a comparison with hysteroscopy. AJR Am J Roentgenol. 2004;183(5):1405-9.
Cite this article as: Yazdani S, Patil D, Mitra S.

Study of HSG findings in our clientele: a multicentre retrospective analytical study. Int J Reprod

Contracept Obstet Gynecol 2022;11:808-16. 